\title{
The importance of juveniles in modelling growth: butterflyfish at Lizard Island
}

\author{
Michael L. Berumen \\ School of Marine Biology and Aquaculture, James Cook University of North Queensland, Townsville, QLD \\ 4811, Australia (e-mail: michael.berumen@jcu.edu.au)
}

Received 12 December $2003 \quad$ Accepted 15 July 2004

Key words: Chaetodontidae, growth curve, von Bertalanffy parameters, coral reef fish, age-based analysis

Synopsis

I established and fitted von Bertalanffy growth functions to size-at-age data for four species of chaetodontids at Lizard Island. Special emphasis on juveniles provided detailed information of the early growth period. All four species demonstrated rapid initial growth achieving an average of $92 \%$ of maximum theoretical size in the first 2 years. I used various constraints of the theoretical age at length zero $\left(t_{0}\right)$ in an analysis of both complete data sets and data sets using only adult fish. An unconstrained value of $t_{0}$ resulted in the best-fit (maximum $r^{2}$ ) curve when juveniles were included. When excluding juveniles, it was necessary to constrain $t_{0}$ to an approximate settling size to most closely represent the growth of the species.

\section{Introduction}

Most studies involving the analysis of age-structure and growth in fishes have focused on temperate, pelagic, or deep-water groups and have made substantial contributions to the management of these groups (Choat \& Robertson 2002). In comparison, the age-based demography of coral reef fishes is poorly studied and understood. The effective management and conservation of fish stocks requires better information on demography and life history features. This is particularly true in the case of coral reef fish where increasing evidence of extended life spans and the decoupling of size and age (e.g., Hart \& Russ 1996, Choat \& Robertson 2002) argues against the use of size-based analyses (Hilborn \& Walters 1992). Given the diversity of coral reef fishes, more comprehensive demographic sampling of the major groups is required before useful generalisations of life histories can be developed (Caley 1998). Studies to date suggest that coral reef fishes demonstrate a wide range of growth patterns and life history traits (Fowler 1995). There are three critical features to be considered: (i) the form of the growth curve and the distribution of somatic growth rates in the life history; (ii) the relationship between size and age; and (iii) the consequences of inadequate sampling of early life history stages. This study examines these issues in four species of chaetodontid fish.

Chaetodontids (butterflyfish) are highly conspicuous and abundant on coral reefs, with more than 120 species in 12 genera throughout the world (Kuiter 2002). Abundances and distributions of butterflyfish have been frequently studied in the context of coral associations (Cadoret et al. 1999, Findley \& Findley 2001) and additionally as potential 'indicator species' of the general state or health of a coral reef (e.g., Crosby \& Reese 1996). However, very little work has been done on the basic growth and life history of these fish (but see Ralston 1976, Fowler 1991). As many chaetodontids have obligate feeding associations with coral (Findley \& Findley 2001), understanding age-based growth rates and longevity will aid in predicting the impacts of resource variation for butterflyfish (Berumen et al. 2004, Pratchett et al. 2004). The current study was conducted because of the importance of understanding how quickly 
juveniles can become established and grow to reproductive size.

I examined growth characteristics of four common species of butterflyfish occurring on tropical coral reefs. The aim of the study was to establish fundamental parameters of growth in the context of an age-based model. Size-at-age data was used to establish the basic form of the growth curve. Previous studies have shown that a lack of data in the earliest growth period of reef fish can lead to greater variability in growth model parameter estimations (Kritzer et al. 2001) and consequently, a special emphasis was placed on including information on juvenile life-stages.

\section{Methods}

I collected samples of Chaetodon baronessa, $C$. citrinellus, C. lunulatus, and C. trifascialis from reefs around Lizard Island $\left(14^{\circ} 40^{\prime} \mathrm{S}, 145^{\circ} 28^{\prime} \mathrm{E}\right)$ in February 2003. Divers on scuba or snorkel collected fish by spearing or netting. Some of the smallest individuals had recently settled into coral colonies and were sheltering within the branches. Divers used a clove oil mixture to anaesthetise these fish and then collected them with hand nets following Munday \& Wilson (1997). I recorded the total length of each fish collected to the nearest $\mathrm{mm}$; removed sagittal otoliths, cleaned them in fresh water, and stored them dry.

I prepared otoliths following Choat \& Axe (1996). I viewed sectioned otoliths using a dissecting microscope (10x) using transmitted light. I counted opaque bands and presumed them to be annular growth deposits (Fowler 1995). I viewed otoliths not clearly displaying two or more rings using a high-power microscope $(400 \times)$ and counted daily increments following Ralston (1976).

I then plotted total length against age for each species. I fitted von Bertalanffy (1938) growth functions and estimated parameters $L_{\infty}$ (theoretical asymptotic length) and $K$ (the index of curvature) by minimising the sum of squares of deviations for a given data set. I examined three values of the parameter $t_{0}$ (age at theoretical length 0 ) for all species. I first constrained $t_{0}$ to ' 0 ,' resulting in a growth curve passing through the origin (indicative that the fish is a length of 0 at age 0 ). I also constrained $t_{0}$ to pass through the $y$-axis at the approximate size of settlement for a given species based on light-trapped sizes and recruit sizes observed on the reef (Stobutzki 1998, Berumen \& Pratchett, unpublished data). Finally, $t_{0}$ was not constrained and I optimised the parameters $K$ and $L_{\infty}$ to produce the best-fit curve for the data, maximizing $r^{2}$. Changing the value of $t_{0}$ inherently changes the parameters $L_{\infty}$ and $K$ as the predicted size-at-age trajectory must be altered to cross the $y$-axis at the appropriate size of settlement $\left(L_{0}\right)$ (Kritzer et al. 2001).

To assess the importance of juveniles in the growth analysis, von Bertalanffy functions were again fitted to the data with all juveniles $(C$. baronessa $<70 \mathrm{~mm}$ total length $\mathrm{TL}, C$. citrinellus $<70 \mathrm{~mm} \mathrm{TL}$, C. lunulatus $<90 \mathrm{~mm} \mathrm{TL}$, C. trifascialis $<75 \mathrm{~mm} \mathrm{TL}$ ) removed from the data set. The various methods of constraint were also again applied as described above.

\section{Results and discussion}

When analysing size at age data for all individuals (including juveniles) of a species, I found that the von Bertalanffy growth functions for all four species had the highest $r^{2}$ values when $t_{0}$ was left unconstrained (Table 1). Kritzer et al. (2001) found that the parameters $L_{\infty}$ and $K$ were always more precise when parameters are constrained, but this was for samples of large reef fish in which early growth information is not well known. In analyses using all individuals, I found that constraining $t_{0}$ to ' 0 ' always produced the lowest $r^{2}$ values (Table 1).

When excluding juveniles from the analysis, I found that $r^{2}$ values were again highest when $t_{0}$ was unconstrained. It is important to note, however, the wide deviation that occurs in these models from the best-fit models (Figure 1). The resultant curves do not produce biologically realistic growth information for any of these species. Of the two constraints for $t_{0}$ that I tested, using an approximate settlement size produced the highest $r^{2}$ values (Table 1).

The patterns of highly asymptotic growth with rapid initial growth I found in butterflyfish (Figure 1) follow a general acanthuroid growth pattern found in many reef fishes (Choat \& Robertson 2002). For example, Choat \& Axe 
Table 1. Parameters and associated values of von Bertalanffy growth functions used to describe growth of four chaetodontid species from Lizard Island. Key: $\mathrm{n}=$ number of individuals in sample; $L_{\infty}=$ theoretical asymptotic length in $\mathrm{mm} ; K=$ index of curvature; $t_{0}=$ theoretical age in years at length $0(x$-intercept $) ; r^{2}=$ Pearson's product coefficient of momentum; $L_{0 \mathrm{c}}=$ constrained settlement size in $\mathrm{mm}$ (length at time 0 ) (constrained $y$-intercept).

\begin{tabular}{|c|c|c|c|c|c|c|c|}
\hline Species & & $n$ & $L_{\infty}$ & $\mathrm{K}$ & $\mathrm{t}_{\mathrm{o}}$ & $r^{2}$ & $L_{0 \mathrm{c}}$ \\
\hline \multirow[t]{6}{*}{ Chaetodon baronessa } & (All individuals) & 36 & 108.2 & 1.104 & 0 & 0.909 & 0 \\
\hline & & & 108.5 & 1.024 & -0.066 & 0.912 & 14 \\
\hline & & & 108.6 & 0.999 & -0.092 & 0.912 & $\mathrm{~N} / \mathrm{A}$ \\
\hline & (Adults only) & 33 & 108.2 & 1.094 & 0 & 0.677 & 0 \\
\hline & & & 108.6 & 0.975 & -0.142 & 0.705 & 14 \\
\hline & & & 112.4 & 0.325 & -3.133 & 0.839 & $\mathrm{~N} / \mathrm{A}$ \\
\hline \multirow[t]{6}{*}{ C. citrinellus } & (All individuals) & 27 & 90.4 & 2.704 & 0 & 0.921 & 0 \\
\hline & & & 90.6 & 2.163 & -0.072 & 0.923 & 13 \\
\hline & & & 90.7 & 2.150 & -0.074 & 0.923 & $\mathrm{~N} / \mathrm{A}$ \\
\hline & (Adults only) & 19 & 93.5 & 1.097 & 0 & 0.283 & 0 \\
\hline & & & 93.8 & 1.002 & -0.149 & 0.300 & 13 \\
\hline & & & 126.0 & 0.083 & -11.482 & 0.471 & $\mathrm{~N} / \mathrm{A}$ \\
\hline \multirow[t]{6}{*}{ C. lunulatus } & (All individuals) & 41 & 104.2 & 3.787 & 0 & 0.828 & 0 \\
\hline & & & 105.1 & 3.054 & -0.05 & 0.858 & 15 \\
\hline & & & 106.9 & 1.941 & -0.241 & 0.882 & $\mathrm{~N} / \mathrm{A}$ \\
\hline & (Adults only) & 28 & 106.4 & 2.550 & 0 & 0.427 & 0 \\
\hline & & & 106.7 & 2.283 & -0.066 & 0.459 & 15 \\
\hline & & & 112.8 & 0.308 & -5.127 & 0.823 & $\mathrm{~N} / \mathrm{A}$ \\
\hline \multirow[t]{6}{*}{ C. trifascialis } & (All individuals) & 37 & 101.8 & 1.974 & 0 & 0.855 & 0 \\
\hline & & & 105.0 & 1.301 & -0.102 & 0.892 & 13 \\
\hline & & & 111.3 & 0.693 & -0.464 & 0.914 & $\mathrm{~N} / \mathrm{A}$ \\
\hline & (Adults only) & 21 & 110.4 & 0.853 & 0 & 0.535 & 0 \\
\hline & & & 111.4 & 0.754 & -0.165 & 0.559 & 13 \\
\hline & & & 134.2 & 0.158 & -4.956 & 0.676 & $\mathrm{~N} / \mathrm{A}$ \\
\hline
\end{tabular}

(1996) found acanthurid fishes achieving $80 \%$ of their growth in $15 \%$ of their lifespan. The species in this study on average attain $92 \%$ of their maximum size within the first 2 years of their life. This suggests that many age-classes would accumulate in a narrow size range, limiting the informative value of size frequencies in demographic analyses (Choat \& Axe 1996) and further emphasising the need for age-based demographic studies suggested by Hilborn \& Walters (1992). Inadequate sampling during the juvenile stage will lead to several complications in analysing the life history of these species. The recruitment process will be difficult to interpret as demographic data will be lacking for the early life stages. Establishing critical aspects of the maturation process will be impossible if reproduction is size based, as is common in reef fish (e.g., Ralston 1981). Finally, using the widely accepted von Bertalanffy growth function analysis of growth, inadequate sampling of juveniles leads to substantial error in parameter estimates.

Ralston (1981) found that C. miliaris attained sexual maturity only at or near maximum size ( $90 \%$ of maximum length). Given the rapid initial growth seen in these four species, it is suspected that chaetodontids attain sexual maturity very early in life. Environmental factors during this rapid initial growth phase may be critical in determining how quickly these fish can establish themselves on a reef and attain maturity (e.g., following a disturbance). In particular, quality or abundance of coral resources may influence this early phase of growth for obligate corallivores (Berumen et al. 2004).

All four of these butterflyfish feed on coral (Randall et al. 1997). C. baronessa and C. trifascialis are extremely specialised and prefer to 

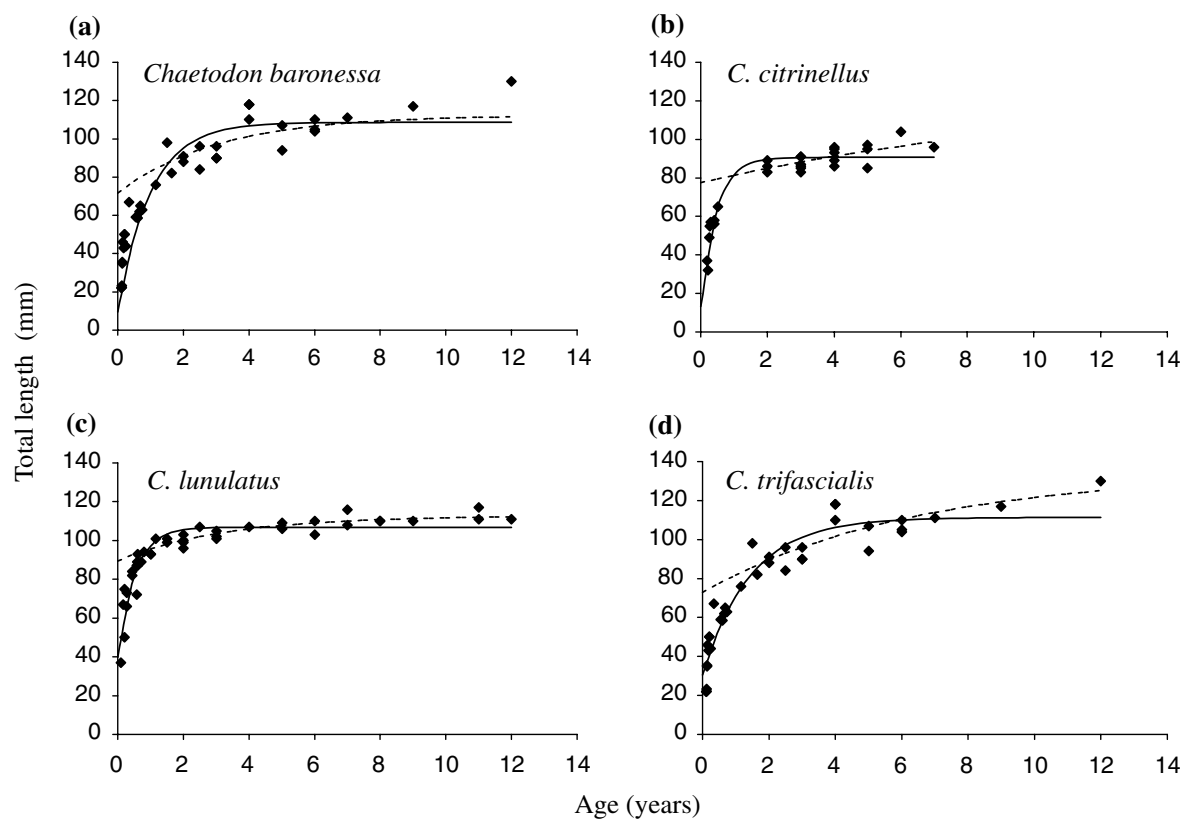

Figure 1. Size-at-age plots for four species of chaetodontids from Lizard Island; (a) Chaetodon baronessa, (b) C. citrinellus, (c) C. lunulatus, (d) C. trifascialis. Solid line represents the best-fit von Bertalanffy growth function using unconstrained parameters of $L_{\infty}, K$, and $t_{0}$ for all individuals. Dashed line represents unconstrained parameters when excluding juveniles from the analysis.

exclusively eat Acropora hyacinthus when it is available (Pratchett 2002, Pratchett et al. 2004). Optimal foraging theory predicts that an animal should only specialise on a resource that conveys the largest overall net gain of energy (Hughes 1980). It could then be predicted that for these specialists, this energy would translate into more rapid growth as a juvenile when compared to a generalist coral feeder such as $C$. citrinellus and $C$. lunulatus. Figure 1 and the respective $K$-values (Table 1) indicate that this prediction does not hold. It is possible that juveniles of these species do not fully realise the benefit of the specialisation until reaching adult size. Alternatively, the higher energy intake may result in a greater level of lipid storage. It seems unlikely that the specialisation is an ontogenetic shift in resource usage as all juveniles observed feeding followed the same preferences as adult fish (Berumen \& Pratchett, unpublished data). Further investigations into the impacts of feeding on juvenile growth will begin to resolve these questions during this critical period of growth.

Constraining $t_{0}$ to ' 0 ' always produced the lowest $r^{2}$ values in analyses using all individuals.
When ample data exists during the early growth of fish rapidly attaining maximum size, it is suggested that constraining $t_{0}$ is not appropriate. When juvenile data is not available, however, constraints are useful to most closely represent a population with rapidly growing juveniles. The most appropriate constraint would be to use a known settlement size. Where this settlement size is not available, constraining settlement size to 0 seems to be the best alternative to approximate the characteristics in the later stages of life, consistent with the findings of Kritzer et al. (2001). Although constraining settlement to a size of 0 is biologically inaccurate, the later stages of life are more accurately represented while the early pattern of growth is also more closely represented despite the lack of sampling during this period.

\section{Acknowledgements}

This study was conducted in partial fulfillment of a Ph.D. program at James Cook University. Field assistance was provided by D. deVere and J. Pitt. 
Comments from J.H. Choat, M.S. Pratchett, and an anonymous reviewer greatly improved the manuscript.

\section{References}

Berumen, M.L., M.S. Pratchett \& M.I. McCormick. 2004. Within-reef differences in diet and body condition of coralfeeding butterflyfishes (Chaetodontidae). Mar. Ecol.-Prog. Ser.

Cadoret, L., M. Aderjoud \& M. Tsuchiya. 1999. Spatial distribution of chaetodontid fish in coral reefs of the Ryukyu Islands, southern Japan. J. Mar. Biol. Assoc. UK. 79: 725735.

Caley, M.J. 1998. Age-specific mortality rates in reef fishes: evidence and implications. Aus. J. Ecol. 23: 241-245.

Choat, J.H., \& L.M. Axe. 1996. Growth and longevity in acanthurid fishes: an analysis of otolith increments. Mar. Ecol.-Prog. Ser. 134: 15-26.

Choat, J. \& D.R. Robertson. 2002. Age-based studies. pp. 5780. In: P. Sale (ed.), Coral Reef Fishes: Dynamics and Diversity in a Complex Ecosystem. Academic Press, San Diego.

Crosby, M.P. \& E.S. Reese. 1996. A manual for monitoring coral reefs with indicator species: Butterflyfishes as indicators of change on Indo Pacific reefs. Office of Ocean and Coastal Resource Management, National Oceanic and Atmospheric Administration, Silver Spring, MD. 45 pp.

Findley, J.S. \& M.T. Findley. 2001. Global, regional, and local patterns in species richness and abundance of butterflyfishes. Ecol. Monogr. 71: 69-91.

Fowler, A.J. 1991. Reproductive biology of bisexual and allfemale populations of chaetodontid fishes from the southern Great Barrier Reef. Environ. Biol. Fish. 31: 261-274.

Fowler, A.J. 1995. Annulus formation in the otoliths of coral reef fish: a review. pp 45-63. In: D.H. Secor, J.M. Dean \& S.E. Campana (ed.), Recent Developments in Fish Otolith Research, University of Southern Carolina Press, Columbia.

Hart, A.M. \& G.R. Russ. 1996. Response of herbivorous fishes to crown-of-thorns starfish Acanthaster planci outbreaks. III.
Age, growth, mortality and maturity indices of Acanthurus nigrofuscus. Mar. Ecol.-Prog. Ser. 136: 25-35.

Hilborn, R. \& C.J. Walters. 1992. Quantitative Fisheries Stock Assessment: Choice, Dynamics, and Uncertainty. Chapman and Hall, New York. 570 pp.

Hughes, R.N. 1980. Optimal foraging theory in the marine context. Oceanpgr. Marine Biol. Ann. Rev. 18: 423-481.

Kritzer, J.P., C.R. Davies \& B.D. Mapstone. 2001. Characterizing fish populations: effects of sample size and population structure on the precision of demographic parameter estimates. Can. J. Fish. Aquat. Sci. 58: 1557-1568.

Kuiter, R.H. 2002. The Marine Fish Families Series: Butterflyfishes, Bannerfishes and their Relatives. A comprehensive Guide to Chaetodontidae and Microcanthidae. TMC Publishing, Chorleywood, UK. 208 pp.

Munday, P.L. \& S.K. Wilson. 1997. Comparative efficacy of clove oil and other chemicals in anaesthetization of Pomacentrus amboiensis, a coral reef fish. J. Fish Biol. 51: 931-938.

Pratchett, M.S. 2002. Dynamics of outbreak populations of crown-of-thorns starfish (Acanthaster planci L.), and their impacts on coral reef ecosystems. Ph.D. thesis, School of Marine Biology and Aquaculture, James Cook University, Townsville, Australia. 201 pp.

Pratchett, M.S., S. Wilson, M.L. Berumen, \& M.I. McCormick. 2004. Sub-lethal effects of coral bleaching on an obligate coral feeding butterflyfish. Coral Reefs 23: 000-000.

Ralston, S. 1976. Age determination of a tropical reef butterflyfish utilizing daily growth rings of otoliths. Fish. Bull. 74: 990-994.

Ralston, S. 1981. Aspects of the reproductive biology and feeding ecology of Chaetodon miliaris, a Hawaiian endemic butterflyfish. Environ. Biol. Fish. 6: 167-176.

Randall, J.E., G.R. Allen \& R.C. Steene. 1997. Fishes of the Great Barrier Reef and Coral Sea. Bathurst, Australia, Crawford House. 507 pp.

Stobutzki, I.C. 1998. Interspecific variation in sustained swimming ability of late pelagic stage reef fish from two families (Pomacentridae and Chaetodontidae). Coral Reefs 17: 111119

von Bertalanffy, L. 1938. A quantitative theory of organic growth. II: Inquiries on growth laws. Hum. Biol. 10: 181213. 